\title{
Review Article \\ CD38/cADPR Signaling Pathway in Airway Disease: Regulatory Mechanisms
}

\author{
Deepak A. Deshpande, ${ }^{1}$ Alonso G. P. Guedes, ${ }^{2}$ Richard Graeff, ${ }^{3}$ Soner Dogan, ${ }^{4}$ \\ Subbaya Subramanian, ${ }^{5}$ Timothy F. Walseth, ${ }^{3}$ and Mathur S. Kannan (iD) ${ }^{6}$ \\ ${ }^{1}$ Department of Medicine, Thomas Jefferson University Medical School, Philadelphia, PA, USA \\ ${ }^{2}$ Department of Veterinary Clinical Science, College of Veterinary Medicine, University of Minnesota, St. Paul, MN, USA \\ ${ }^{3}$ Department of Pharmacology, University of Minnesota Medical School, Minneapolis, MN, USA \\ ${ }^{4}$ Department of Medical Biology, Yeditepe University School of Medicine, Istanbul, Turkey \\ ${ }^{5}$ Department of Surgery, University of Minnesota Medical School, Minneapolis, MN, USA \\ ${ }^{6}$ Department of Veterinary and Biomedical Sciences, College of Veterinary Medicine, University of Minnesota, St. Paul, MN, USA
}

Correspondence should be addressed to Mathur S. Kannan; kanna001@umn.edu

Received 29 September 2017; Accepted 26 December 2017; Published 7 February 2018

Academic Editor: Roberta Rizzo

Copyright ( 2018 Deepak A. Deshpande et al. This is an open access article distributed under the Creative Commons Attribution License, which permits unrestricted use, distribution, and reproduction in any medium, provided the original work is properly cited.

\begin{abstract}
Asthma is an inflammatory disease in which proinflammatory cytokines have a role in inducing abnormalities of airway smooth muscle function and in the development of airway hyperresponsiveness. Inflammatory cytokines alter calcium $\left(\mathrm{Ca}^{2+}\right)$ signaling and contractility of airway smooth muscle, which results in nonspecific airway hyperresponsiveness to agonists. In this context, $\mathrm{Ca}^{2+}$ regulatory mechanisms in airway smooth muscle and changes in these regulatory mechanisms encompass a major component of airway hyperresponsiveness. Although dynamic $\mathrm{Ca}^{2+}$ regulation is complex, phospholipase $\mathrm{C} /$ inositol tris-phosphate (PLC/IP3) and CD38-cyclic ADP-ribose (CD38/cADPR) are two major pathways mediating agonist-induced $\mathrm{Ca}^{2+}$ regulation in airway smooth muscle. Altered CD38 expression or enhanced cyclic ADP-ribosyl cyclase activity associated with CD38 contributes to human pathologies such as asthma, neoplasia, and neuroimmune diseases. This review is focused on investigations on the role of CD38-cyclic ADP-ribose signaling in airway smooth muscle in the context of transcriptional and posttranscriptional regulation of CD38 expression. The specific roles of transcription factors NF-kB and AP-1 in the transcriptional regulation of CD38 expression and of miRNAs miR-140-3p and miR-708 in the posttranscriptional regulation and the underlying mechanisms of such regulation are discussed.
\end{abstract}

\section{Introduction}

Asthma is an inflammatory disease in which proinflammatory cytokines have a role in inducing abnormalities of airway smooth muscle (ASM) function and in the development of airway hyperresponsiveness (AHR). Airway smooth muscle obtained from asthmatics is different from smooth muscle obtained from healthy subjects [1]. Inflammatory cytokines alter calcium $\left(\mathrm{Ca}^{2+}\right)$ signaling and contractility of ASM, which results in nonspecific AHR to agonists [2-4]. The increased ASM mass and heightened contractile response of ASM in asthmatic subjects contribute to airway narrowing during an asthma episode [5]. The molecular pathogenesis of asthma includes modulation of expression, activity, or sensitivity of intracellular signaling molecules and effector targets in ASM cells. Studies of gene expression in airway biopsies from mild allergic asthmatics reveal increased expression of contractile proteins and proteins involved in the regulation of these proteins, leading to faster velocity of actin filament propulsion and AHR [6]. Furthermore, ASM cells from asthmatics proliferate at a higher rate and are resistant to antimitogenic effect of glucocorticoids, secrete chemokines, and attain a hypercontractile phenotype [7-9]. In this context, $\mathrm{Ca}^{2+}$ regulatory mechanisms in ASM and changes in these regulatory mechanisms encompass a major component of AHR. Although 
dynamic $\mathrm{Ca}^{2+}$ regulation is complex, phospholipase $\mathrm{C} /$ inositol tris-phosphate (PLC/IP3) and CD38-cyclic ADP-ribose (CD38/cADPR) are two major pathways mediating agonistinduced $\mathrm{Ca}^{2+}$ regulation in ASM. We will focus our discussion on CD38/cADPR pathway in this review.

The CD38 gene encodes a glycosylated $\sim 45 \mathrm{kDa}$ type II transmembrane protein whose enzymatic activity generates CADPR and adenosine diphosphoribose (ADPR) from $\mathrm{NAD}^{+}$and nicotinic acid adenine dinucleotide phosphate (NAADP) from NADP ${ }^{+}$. The cADPR and NAADP regulate $\mathrm{Ca}^{2+}$ signaling and contractility in smooth muscle cells [2]. Extracellular ADP-ribosyl cyclase activity of CD38 leads to generation of cADPR outside the cells that is believed to enter cells via membrane channels formed by CD38 dimers or connexin-43 [10, 11]. Interestingly, recent studies have provided evidence for expression of type III CD38 in human multiple myeloma cells wherein the catalytic domain of the molecule is cytoplasmic and amenable to cytosolic regulation [12]. Furthermore, site-directed mutagenesis of the cationic amino acid residues in the amino-terminal region of CD38 results in the conversion from a mixture of type II and type III orientations to predominantly type III. Recombinant expression of the type III CD38 in a heterologous cell system led to elevation of intracellular concentrations of cADPR [13]. Whether type III CD38 is expressed on ASM membranes and its contribution to cADPR-mediated calcium release needs additional investigation.

Using pharmacological and genetic approaches in human cells and tissues, and murine models of asthma, we have demonstrated the contribution of CD38-cADPR to ASM $\mathrm{Ca}^{2+}$ signaling and contractility. Airway myocytes from CD38 knockout (CD38KO) mice exhibit attenuated intracellular $\mathrm{Ca}^{2+}\left(\left[\mathrm{Ca}^{2+}\right]_{\mathrm{i}}\right)$ responses to agonists [2] and methacholine-induced airway responsiveness in the CD38KO mice is lower than in wild-type (WT) mice. Alteration in CD38 expression and/or modulation of enzyme activities associated with CD38 result in altered $\mathrm{Ca}^{2+}$ signaling and contractility of ASM. In murine models of asthma, we demonstrated the role of CD38 in allergen-induced airway inflammation and AHR. CD38KO mice develop attenuated AHR following allergen, IL-13, or TNF- $\alpha$ challenge [14-16]. It is important to note that CD38 is also expressed on immune cells that are important in humoral and cellmediated immune response in asthma [17]. Reconstitution of WT bone marrow in the $\mathrm{CD} 38 \mathrm{KO}$ mice partially restores the WT airway phenotype following allergen sensitization and challenge [18]. This suggests that $\mathrm{CD} 38^{+}$inflammatory cells that are recruited into the lungs following allergen challenge are sufficient to impart the WT airway phenotype in the CD38KO mice. These findings implicate CD38 in the pathophysiology of asthma. CD38 has been implicated in other human pathologies including in neuroinflammatory diseases, renal dysfunctions, neoplastic disorders, and viral infections (respiratory syncytial virus) [19-22].

Inflammatory cytokines such as IL-13 and TNF- $\alpha$, which are implicated in asthma, augment CD38 expression and cADPR-mediated $\mathrm{Ca}^{2+}$ release and increase contractility of ASM. ASM cells obtained from subjects who died from an episode of asthma or subjects with a history of stable asthma show significantly enhanced expression of CD38 (both transcript and protein) to low concentrations of TNF- $\alpha$ compared to expression in cells from nonasthmatics [5]. This is significant since the TNF- $\alpha$ axis does have a role in asthma that is refractory to current therapy, and TNF- $\alpha$ levels in bronchoalveolar lavage (BAL) fluid are elevated in patients with severe asthma [23-26]. These observations collectively indicate that the capacity for CD38/cADPR signaling in $\left[\mathrm{Ca}^{2+}\right]_{\mathrm{i}}$ regulation and contractility of ASM is significantly greater in asthmatic ASM cells than in cells derived from nonasthmatic subjects. This might arise due to altered CD38 expression and/or modulation of enzyme activities associated with CD38. Therefore, we have examined the transcriptional and posttranscriptional regulation of expression of CD38 in human ASM cells obtained from asthmatics and healthy subjects. Specifically, the role of several transcription factors and miRNAs in the regulation of CD38 expression was examined in these studies. Of note, the contribution of CD38 to $\left[\mathrm{Ca}^{2+}\right]_{\mathrm{I}}$ regulation and the underlying mechanisms of such regulation have been addressed in several prior publications and will not be considered here. This review will focus on the role of various transcription factors and specific miRNAs in the regulation of CD38 expression in ASM (Figure 1).

\section{CD38 Gene Organization, Polymorphisms, and Human Diseases}

In the human and mouse, the gene encoding CD38 (CD38, human; $c d 38$, mouse) is localized on chromosomes 4 and 5, respectively [27]. The CD38 polypeptide is encoded by a $>80 \mathrm{kbp}$ length gene comprising 8 exons, more than $98 \%$ being represented by intronic sequences. We have cloned the promoter region of CD38 (Acc. number DQ091293), and sequence analysis reveals putative $\mathrm{NF}-\kappa \mathrm{B}, \mathrm{AP}-1, \mathrm{C} / \mathrm{EBP} \beta$, glucocorticoid response element (GRE), and an estrogen response motif [28]. Inducible elements are reported in the $5^{\prime}$ end of intron 1 . In addition, intron 1 is reported to have a DR5 repeat, the retinoid acid response element, and a $900 \mathrm{bp} \mathrm{CpG}$ island associated with exon 1 and the $5^{\prime}$ end of intron 1 [29]. Binding of Sp1 to the CpG motif appears to maintain it in an unmethylated state and this allows for constitutive expression of CD38 in cells. These response elements and transactivating regulatory sequences within the CD38 gene allow for transcriptional regulation by a diverse array of factors and mechanisms [29-31]. In different cell types, CD38 expression is induced by retinoic acid through the retinoic acid response element located within intron 1 of the CD38 gene [32]. Single nucleotide polymorphisms in regulatory or protein coding regions of CD38 presumably alter CD38 expression. A polymorphism in intron 1 of the human CD38 has been described [27]. The absence or presence of a PvuII site defines two alleles, a $C D 38^{*} \mathrm{~A}$ allele and a $C D 38^{*} \mathrm{~B}$ allele. Ferrero et al. have identified that in the Italian Caucasian population, the $C D 38^{*} \mathrm{~B}$ allele appears to be more frequent than the CD38*A allele [27]. Okamoto's group has also described a mutation in exon 4 of CD38 in some subjects with type 
Regulation of CD38 expression or enzyme activity

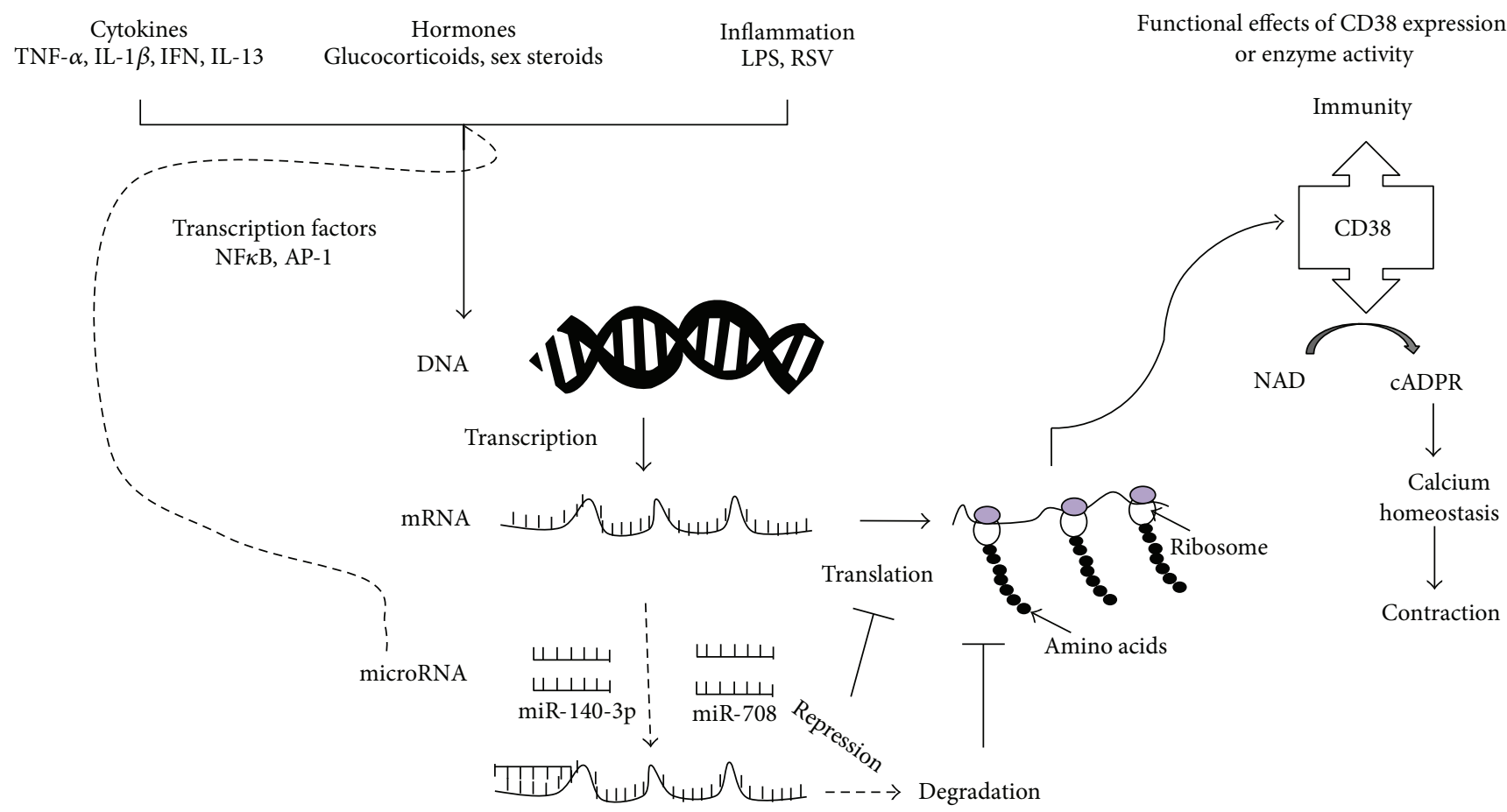

FIGURE 1: Regulation of expression and functional role of CD38. Bifunctional enzyme CD38 is expressed on a variety of immune and mesenchymal cells including on airway smooth muscle cells. In immune cells, CD38 serves as a cell surface marker and contributes to inflammatory response. CD38 via production of cADPR, a calcium elevating second messenger, contributes to smooth muscle contractility and airway hyperresponsiveness (right half). Regulating CD38 expression, its enzyme activity or cADPR levels in effector cells may lead to human pathologies. Inflammatory cytokines, hormones, and other inflammatory mediators regulate CD38 expression via activation of transcription factors such as NF- $\kappa$ B and AP-1 or via expression of specific microRNAs (left half). Overall, CD38 expression can be modulated at transcriptional level as well as posttranscriptionally by microRNAs.

II diabetes mellitus [33]. CD38 is implicated in the oxytocin signaling pathway, and single nucleotide polymorphisms in this gene have been associated with low serum oxytocin levels in autism spectrum disorder (ASD) patients $[19,34,35]$. Disruption of oxytocin signaling has been associated with features of ASD, including impaired communication and social behavior, based on animal studies. Whether polymorphisms in the CD38 gene are associated with asthma in humans remain to be determined. In this context, a recent report has identified an individual with autism and asthma with an inherited maternal deletion of 4p15.32 resulting in a BST1-CD38 fusion transcript [36]. This is the first report that describes rearrangements involving CD38 or deletions in patients with ASD.

\section{Regulation of CD38 Expression in ASM Cells: Role of Transcriptional Mechanisms and Signaling Crosstalk}

In prior studies, we demonstrated augmented CD38 expression, ADP-ribosyl cyclase activity, cADPR production, and $\left[\mathrm{Ca}^{2+}\right]_{\mathrm{i}}$ responses to agonists in human ASM cells by IL-13 and TNF- $\alpha[2-4,15,16]$. Effects of inflammatory cytokines on CD38 expression and CADPR-mediated calcium release in human ASM cells have been studied by other investigators [37-41]. These data suggest that CD38 expression is regulated by cytokines in ASM cells (Figure 1). Numerous studies have unequivocally demonstrated the central role of inflammatory and Th2 cytokines in asthma [42]. Furthermore, mice challenged intranasally with IL-13 or TNF- $\alpha$ exhibited significantly greater airway inflammation, BAL cytokine levels, and augmented methacholine-induced changes in airway resistance. These changes in the airways were significantly attenuated in the CD38KO mice compared to responses in the WT mice. These observations strongly implicate CD38 in the pathophysiology of asthma in the mouse models and that IL-13 and TNF- $\alpha$ alter ASM functions [43-45] in part via CD38.

Evidence for TNF- $\alpha$ in the pathogenesis of allergic airway disease comes from the following observations. Human clinical trials with anti-TNF- $\alpha$-immunomodulators (etanercept) and anti-TNF- $\alpha$ monoclonal antibodies (infliximab) have shown that TNF- $\alpha$ has a role in asthma that is refractory to corticosteroids [42]. TNF- $\alpha$ secretion following allergen challenge is higher in atopic asthmatics (i.e., asthmatics with allergy) than in nonatopics (asthmatics with no clearly defined allergy) $[46,47]$. Aerosolized TNF- $\alpha$ to human volunteers causes AHR [48-50]. In vitro tissue studies have shown that TNF- $\alpha$ treatment increases contractility and 
$\mathrm{Ca}^{2+}$ signaling in ASM cells [15]. The effects of TNF- $\alpha$ in corticosteroid-resistant asthma may be mediated by direct effects to alter the dynamics of the $\mathrm{Ca}^{2+}$ response to agonists and thereby the contractility of the ASM. TNF- $\alpha$ induces ASM cell synthesis and release of IL-8 and eotaxin, and upregulates the expression of adhesion molecules, receptors for inflammatory mediators, and growth factors $[51,52]$. A polymorphism in the $5^{\prime}$ untranslated region of the TNF gene (G$308 \mathrm{~A}$ ), referred to as TNF-308 GG genotype, is associated with inflammatory diseases including asthma [53].

We have also observed that among the cytokines that are implicated in asthma, TNF- $\alpha$ causes the greatest induction of CD38 expression in ASM cells $[3,5]$. Furthermore, a single intranasal challenge with TNF- $\alpha$ causes significant augmentation of methacholine-induced airway resistance in the WT but not in the CD38KO mice [15]. Therefore, we examined the regulation of CD38 expression in airway myocytes obtained from asthmatic and healthy human subjects in an attempt to identify signaling intermediates involved in this process and to identify potential therapeutic targets. Other investigators have demonstrated that CD38 expression is altered by other cytokines such as type I interferons and lipopolysaccharide (LPS) in many other cell types including epithelial cells, renal cells, macrophages, and other immune cells $[19,22]$.

Sequence analysis of a $3 \mathrm{~kb}$ putative $C D 38$ promoter fragment (Gen-Bank accession number DQ091293) cloned from a human erythropoietic cell line (K562 cells) in our laboratory revealed binding sites for NF- $\kappa \mathrm{B}, \mathrm{AP}-1$, and glucocorticoid receptor (GR). To determine whether CD38 expression in human ASM cells is regulated by TNF- $\alpha$ and GRE, we measured the binding of transcription factors and the GR to their respective putative sites within this promoter region $[28,54]$. Our results demonstrate that TNF- $\alpha$ causes increased binding to the NF- $\kappa \mathrm{B}$ site and to 3 of the 6 putative AP-1 sites. Site-directed mutagenesis of the AP-1 site that exhibited very strong binding of nuclear proteins (AP-1 site 4) or the NF- $\mathrm{KB}$ site abolished promoter activation induced by TNF- $\alpha$. Regulation of the CD38 gene has also been investigated in human myeloid cells [32]. In these cells, CD38 expression is induced by retinoic acid through the retinoic acid response element located within the first intron of the CD38 gene. Response elements for other transcription factors, including AP-1, have been described in osteoblasts and osteoclasts [31], and in these cell lines, TNF- $\alpha$-induced activation of a CD38 promoter fragment requires an intact AP-1 site.

Glucocorticoids are widely used in the management of inflammatory airway diseases $[55,56]$. The mechanisms of action of glucocorticoids are complex and involve transcription factors, including NF- $\kappa \mathrm{B}[56,57]$. The glucocorticoid dexamethasone increased the binding of GR to 3 of the 4 putative GRE sites within the CD38 promoter and abolished promoter activation induced by TNF- $\alpha$ [28, 54]. These results demonstrate that TNF- $\alpha$ regulates CD38 expression transcriptionally through NF- $\kappa \mathrm{B}$ and AP-1 (Figure 1), and glucocorticoids decrease this expression possibly by binding to GREs within the CD38 promoter and/or also by decreased NF- $\kappa$ B- and AP-1-mediated transcription $[28,54]$.
Interestingly, Tliba et al. demonstrated that CD38 augmenting effect of TNF- $\alpha$ in human ASM cells is insensitive to glucocorticoid treatment, and this steroid resistance involves action of interferon regulatory factor (IGF)-1 and glucocorticoid receptor $\beta(\mathrm{GR}-\beta)$ isoform [38, 58].

The mechanisms by which mitogen-activated protein (MAP) kinases mediate changes in gene expression are complex and involve the interaction of several proteins and transcription factors. In ASM cells, MAPKs mediate changes in the profile of gene expression through phosphorylation of intracellular proteins including transcription factors, and TNF- $\alpha$ causes activation of the MAPKs, that is, p38, JNK, and ERK1/2, resulting in the regulated expression of a variety of genes involved in excitation-contraction coupling [59-65]. NF- $\kappa$ B mediates the effects of TNF- $\alpha$ in ASM and other cell types. Repression of transcription of proinflammatory genes by glucocorticoids involves binding to GREs within the promoter region and through interaction with transcription factors. With respect to interaction of GR and regulation through AP-1 and NF- $\kappa \mathrm{B}$, evidence supports direct interaction between the proteins rather than inhibition of binding of transcription factors to their respective response elements [66-71]. GR binding to cisacting elements and the trans-acting factors that bind these are essential for a complete glucocorticoid response. The anti-inflammatory effects of glucocorticoids may be distinct from the effects on gene transcription and may involve the MAPK pathways. Glucocorticoids can induce the expression of a dual specificity phosphatase 1 (DUSP1), also known as MAPK phosphatase 1 (MKP-1) [60, 61, 72-74]. MKP-1 causes dephosphorylation and inactivation of the activated MAPKs. Thus, MKP-1 induction is considered as an important anti-inflammatory action of glucocorticoids. MAPKs also regulate the stability of mRNAs for several proinflammatory cytokines. We have systematically examined the role of MAP kinases and glucocorticoids in TNF- $\alpha$-mediated CD38 expression in human cells. We also examined whether the differential induction of CD38 expression in asthmatic ASM cells can be attributed to differential activation of MAP kinases. Exposure to TNF- $\alpha$ caused a rapid phosphorylation of all three MAP kinases. Dexamethasone decreased TNF- $\alpha$-induced phosphorylation of the MAP kinases and increased MKP-1 expression. These effects of dexamethasone resulted in significant attenuation of $\mathrm{CD} 38$ expression. Furthermore, in cells transfected with MKP-1-specific small interfering RNAs, there was significant attenuation of MKP-1 expression and partial reversal of dexamethasone inhibition of CD38 expression. These findings indicate that regulation of CD38 expression in human ASM cells by glucocorticoids involves decreased signaling through MAP kinases and activation of transcription factors. Glucocorticoid effects on inhibition of CD38 expression involve both transcriptional and posttranscriptional mechanisms, the latter through alteration of transcript stability. In human ASM cells, p38 and ERK MAPKs are involved in CD38 transcript stability, while the JNK MAPK is involved in transcriptional regulation of $\mathrm{CD} 38$ expression. The $3^{\prime} \mathrm{UTR}$ of $\mathrm{CD} 38 \mathrm{mRNA}$ contains $\mathrm{A} / \mathrm{U}$ rich elements and their role in $\mathrm{CD} 38 \mathrm{mRNA}$ stability remains to be determined. 
Phosphatidylinositol-3 kinase/Akt pathway (PI3 kinase) is a key component of intracellular signaling pathways activated by cytokines, growth factors, and glucocorticoids in ASM cell $[75,76]$. Binding of TNF- $\alpha$ to TNFR1 resulting in the activation of NF- $\kappa \mathrm{B}$ and the MAPK signaling pathways results in induction of $C D 38$ gene $[63,77]$. We have examined the role of PI3 kinases in the regulation of CD38 expression and function in human ASM cells [78]. Since our previous studies showed a differential induction of CD38 expression by TNF- $\alpha$ in ASM cells derived from asthmatic subjects, we determined whether PI3Ks are involved in this differential induction. Cells were treated with pan-PI3K inhibitors or class I-selective or isoform-selective PI3K inhibitors with and without TNF- $\alpha$. In other studies, we transfected the cells with a catalytically active form of PI3K or PTEN or nontargeting or p110 isoform-targeting siRNAs before exposure to TNF- $\alpha$ and measured CD38 expression, ADP-ribosyl cyclase activity, and activation of Akt, NF- $\kappa \mathrm{B}$, and AP-1. TNF- $\alpha$-induced CD38 expression and enzyme activity and Akt activation were inhibited by a pan-PI3K inhibitor. P110 expression by transient transfection increased Akt activation, and basal and TNF- $\alpha$-induced CD38 expression, while PTEN expression attenuated Akt activation and CD38 expression. Silencing of $\mathrm{p} 110 \alpha$ or $-\delta$ isoform by siRNAs caused a reduction in TNF- $\alpha$-induced CD38 expression in asthmatic and nonasthmatic ASM cells to a comparable magnitude. Furthermore, the PI3K inhibitors had no significant effect on NF- $\kappa \mathrm{B}$ or $\mathrm{AP}-1$ activation. These results indicated that in human ASM cells, regulation of CD38 expression is mediated through class I PI3K isoforms, but PI3K signaling may not be involved in the differential induction of CD38 in asthmatic ASM cells.

In addition to the mechanisms of regulation of CD38 in ASM described above, there is also evidence for hormonal regulation in other smooth muscles. In this context, we previously reported estrogen regulation of CD38 expression in myometrium smooth muscle [79-81]. In ovariectomized rats treated with estrogen, there was enhanced expression of CD38 in the myometrium compared to expression in control rats. Furthermore, when we compared CD38 expression in the myometrium obtained from preterm versus term rats, there was significantly greater expression in the term rat myometrium compared to expression in preterm rat myometrium. CD38 expression in preterm myometrium was comparable to expression in myometrium obtained from ovariectomized rats or from ovariectomized rats treated with both estrogen and progesterone. The augmented CD38 expression in the myometrium of term rats or ovariectomized rats treated with estrogen was associated with enhanced ADP-ribosyl cyclase but not cADPR hydrolase activity, suggesting a differential regulation involving posttranslational modification of the protein. However, the nature of this posttranslational regulation of CD38 enzyme activities is not currently known. Other hormones that might be involved in the regulation of ADP-ribosyl activity include betamethasone and L-thyroxine. Treatment of renal cells with thyroxine augments ADP-ribosyl cyclase and cADPR generation and contributes to nephrotoxicity [82]. The role of retinoic acid in modulating CD38 expression and CADPR levels in many cell types has been investigated extensively [32, 83]. Betamethasone, another hormone, administered antenatally in sheep model leads to increased CD38 expression and contributes to postnatal hypertension suggesting a potential augmenting effect of CD38 in peripheral vascular resistance [84].

\section{Posttranscriptional Regulation of CD38 Expression: Role of MicroRNAs (miRNAs)}

miRNAs are noncoding $\sim 22 \mathrm{nt}$ RNAs that have a central role in posttranscriptional regulation of expression of genes involved in inflammation and other cellular functions [85-89]. miRNAs regulate gene expression by destabilizing the transcripts or by translational repression [90]. Evidence has emerged for their role in airway diseases such as asthma, COPD, and idiopathic pulmonary fibrosis [91, 92]. miR-21 appears to have a role in Th1/Th2 immune responses to antigen, suggesting a role in the pathogenesis of allergic asthma. Other investigations have shown that let-7 and miR-155 regulate IL-13 signaling and miR-133 in RhoA expression, thus highlighting their potential role in airway inflammation and AHR [85-88]. Web-based target prediction algorithms were used to determine potential miRNA response elements in the CD38 $3^{\prime}$-untranslated region (3'UTR). Although the target prediction resulted in the identification of several potential miRNA targets in the $3^{\prime} \mathrm{UTR}$, quantitative RT-PCR showed expression of miR-140-3p and miR-708. Therefore, we chose to examine the contribution of these two miRNAs to posttranslational regulation of CD38 expression in human ASM cells. We employed luciferase reporter assays to determine miR-140-3p and miR-708 binding to the CD38 $3^{\prime}$ UTR. In human ASM cells transfected with miR-140-3p or miR-708 mimics, CD38 mRNA expression and ADP-ribosyl cyclase activity were significantly attenuated compared to expression and enzyme activity in cells transfected with a control oligonucleotide. Site-directed mutagenesis of the miRNA binding sites on the CD38 $3^{\prime}$ UTR reversed the inhibition of luciferase activity induced by the miRNA mimics. We then determined whether the differential induction of CD38 in cells from asthmatic airways could be attributed to differential induction of expression of miRNAs. Exposure to TNF- $\alpha$ caused a reduction in the expression of miR-140-3p and miR-708 to a comparable magnitude in cells from asthmatics and nonasthmatics. Furthermore, stability of the CD38 transcript was unaltered by overexpression of the miRNAs. These findings suggest that the reduction of CD38 expression may arise to a large extent from indirect mechanisms and that the differential induction of CD38 expression in asthmatic ASM cells may not be attributed to differences in miRNA levels following exposure to TNF- $\alpha[93,94]$ (Figure 1).

Previous studies showed that MAP kinases are involved in the regulation of CD38 expression in human ASM cells. Therefore, we examined the activation of the MAPKs following transfection of cells with the miRNAs. In cells transfected with the miR-140-3p mimic, there was decreased TNF- $\alpha$ induced activation of p38 MAPK and NF- $\kappa$ B. On the other hand, miR-708 transfection caused a reduction in JNK 
MAPK activation and Akt activation. Transfection with miR708 also resulted in induction of MKP-1 and PTEN, phosphatases that are involved in dephosphorylation of MAPKs and PI3K signaling, respectively [94]. Prior reports have provided evidence that PTEN expression in certain cancer cells is regulated by miRNAs $[95,96]$. For example, miR-221 and miR-222 inhibit PTEN expression by binding to the $3^{\prime} \mathrm{UTR}$, while knockdown of these miRNAs increases PTEN expression. Furthermore, regulation of PTEN expression in these cancer cells has a direct effect on tumor cell proliferation, migration, and invasion. There is evidence that the PI3K/ Akt signaling pathway has a major contribution to ASM proliferation in asthmatics $[75,76]$. Therefore, we hypothesize that by regulating the expression of PTEN and thereby the PI3K/Akt signaling pathway, miR-708 may have a profound impact on cell proliferation and airway wall remodeling. These findings strongly indicate that indirect mechanisms are involved in the actions of miRNAs in the regulation of CD38 expression and in the control of airway inflammation and ASM proliferation.

\section{Conclusions}

This review outlines the transcriptional and posttranscriptional mechanisms of regulation of CD38 expression and function in ASM. Using the promoter-luciferase transfection system and site-directed mutagenesis approaches, we have demonstrated the critical role of NF- $\kappa$ B and AP-1 transcription factors in such regulation. Cytokines and steroid (glucocorticoids, sex steroids) hormones modulate CD38 expression in ASM. Our studies on CD38 expression in the myometrium show estrogen regulation and inhibition of expression by progesterone. Furthermore, during gestation, CD38 expression in the myometrium is maintained at a relatively low level until very close to term when the ratio of estrogen to progesterone is high. An interesting observation of these studies is that estrogen-mediated augmented CD38 expression causes a differential regulation of the catalytic activities of the enzyme, the mechanisms underlying this being not well defined. In human ASM cells obtained from fatal asthmatics, TNF- $\alpha$ induces a significantly greater induction of CD38 expression compared to expression in cells obtained from nonasthmatic subjects. This differential induction of CD38 expression suggests that the capacity for cADPR-mediated calcium regulation is significantly greater in asthmatic airway smooth muscle cells compared to cells from healthy subjects. In this context, our previous studies showed that exposure to TNF- $\alpha$ results in significantly greater airway responsiveness to inhaled methacholine in the WT than in the CD38KO mice. Furthermore, CD38KO mice fail to develop an asthmatic airway phenotype following sensitization and challenge with allergen as well as following intranasal challenge with IL-13, a Th2 cytokine implicated in the pathogenesis of asthma. Our recent studies showed that transfer of bone marrow from WT mice to CD38KO mice partially restores the WT phenotype following allergen sensitization and challenge. These findings support the concept that CD38 expressions in airway structural cells and inflammatory cells recruited into the lungs following allergen challenge are both critical for the development of an asthmatic phenotype. The investigations on the posttranscriptional regulation of CD38 expression provide evidence for two specific miRNAs in such regulation. The mechanisms by which miR-140-3p and miR-708 mediate the inhibitory effect on CD38 expression are different. While miR-140-3p effects on downregulation of CD38 expression in human ASM cells are mediated via inhibition of p38 MAPK and NF- $\kappa \mathrm{B}$ activation, the effects of miR-708 effects are via inhibition of JNK MAPK and PI3K activation, the latter by increased expression of PTEN. Dysregulation of expression of these two miRNAs should have profound effects on CD38 expression and airway function.

\section{Conflicts of Interest}

The authors declare that there is no conflict of interest regarding the publication of this article.

\section{Acknowledgments}

Mathur S. Kannan and Deepak A. Deshpande received support through grants from the National Institutes of Health.

\section{References}

[1] O. Tliba and R. A. Panettieri Jr, "Noncontractile functions of airway smooth muscle cells in asthma," Annual Review of Physiology, vol. 71, no. 1, pp. 509-535, 2009.

[2] D. A. Deshpande, T. A. White, S. Dogan, T. F. Walseth, R. A. Panettieri, and M. S. Kannan, " $\mathrm{CD}_{3} 8 /$ cyclic ADP-ribose signaling: role in the regulation of calcium homeostasis in airway smooth muscle," American Journal of Physiology-Lung Cellular and Molecular Physiology, vol. 288, no. 5, pp. L773-L788, 2005.

[3] D. A. Deshpande, T. F. Walseth, R. A. Panettieri, and M. S. Kannan, " $\mathrm{CD}_{3} 8$-cyclic ADP-ribose-mediated $\mathrm{Ca} 2+$ signaling contributes to airway smooth muscle hyper-responsiveness," The FASEB Journal, vol. 17, no. 3, pp. 452-454, 2003.

[4] D. A. Deshpande, S. Dogan, T. F. Walseth et al., "Modulation of calcium signaling by interleukin-13 in human airway smooth muscle: role of CD38/cyclic adenosine diphosphate ribose pathway," American Journal of Respiratory Cell and Molecular Biology, vol. 31, no. 1, pp. 36-42, 2004.

[5] J. A. Jude, J. Solway, R. A. Panettieri Jr., T. F. Walseth, and M. S. Kannan, "Differential induction of CD38 expression by TNF- $\alpha$ in asthmatic airway smooth muscle cells," American Journal of Physiology-Lung Cellular and Molecular Physiology, vol. 299, no. 6, pp. L879-L890, 2010.

[6] R. Leguillette, M. Laviolette, C. Bergeron et al., "Myosin, transgelin, and myosin light chain kinase: expression and function in asthma," American Journal of Respiratory and Critical Care Medicine, vol. 179, no. 3, pp. 194-204, 2009.

[7] X. Ma, Z. Cheng, H. Kong et al., "Changes in biophysical and biochemical properties of single bronchial smooth muscle cells from asthmatic subjects," American Journal of PhysiologyLung Cellular and Molecular Physiology, vol. 283, no. 6, pp. L1181-L1189, 2002.

[8] P. R. Johnson, M. Roth, M. Tamm et al., "Airway smooth muscle cell proliferation is increased in asthma," American Journal 
of Respiratory and Critical Care Medicine, vol. 164, no. 3, pp. 474-477, 2001.

[9] G. Damera, H. W. Fogle, P. Lim et al., "Vitamin D inhibits growth of human airway smooth muscle cells through growth factor-induced phosphorylation of retinoblastoma protein and checkpoint kinase 1," British Journal of Pharmacology, vol. 158, no. 6, pp. 1429-1441, 2009.

[10] E. K. Song, S. Y. Rah, Y. R. Lee et al., "Connexin-43 hemichannels mediate cyclic ADP-ribose generation and its $\mathrm{Ca}^{2+}$-mobilizing activity by $\mathrm{NAD}^{+} /$cyclic ADP-ribose transport," The Journal of Biological Chemistry, vol. 286, no. 52, pp. 44480-44490, 2011.

[11] T. Hattori, M. Kaji, H. Ishii et al., "CD38 positively regulates postnatal development of astrocytes cell-autonomously and oligodendrocytes non-cell-autonomously," Glia, vol. 65, no. 6, pp. 974-989, 2017.

[12] J. Liu, Y. J. Zhao, W. H. Li et al., "Cytosolic interaction of type III human CD38 with CIB1 modulates cellular cyclic ADPribose levels," Proceedings of the National Academy of Sciences of the United States of America, vol. 114, no. 31, pp. 8283-8288, 2017.

[13] Y. J. Zhao, C. M. Lam, and H. C. Lee, “The membrane-bound enzyme CD38 exists in two opposing orientations," Science Signaling, vol. 5, no. 241, article ra67, 2012.

[14] D. A. Deshpande, T. A. White, A. G. Guedes et al., "Altered airway responsiveness in CD38-deficient mice," American Journal of Respiratory Cell and Molecular Biology, vol. 32, no. 2, pp. 149-156, 2005.

[15] A. G. Guedes, J. A. Jude, J. Paulin, H. Kita, F. E. Lund, and M. S. Kannan, "Role of CD38 in TNF- $\alpha$-induced airway hyperresponsiveness," American Journal of Physiology. Lung Cellular and Molecular Physiology, vol. 294, no. 2, pp. L290-L299, 2008.

[16] A. G. Guedes, J. Paulin, L. Rivero-Nava, H. Kita, F. E. Lund, and M. S. Kannan, "CD38-deficient mice have reduced airway hyperresponsiveness following IL-13 challenge," American Journal of Physiology-Lung Cellular and Molecular Physiology, vol. 291, no. 6, pp. L1286-L1293, 2006.

[17] F. E. Lund, "Signaling properties of CD38 in the mouse immune system: enzyme-dependent and -independent roles in immunity," Molecular Medicine, vol. 12, no. 11-12, pp. 328-333, 2006.

[18] A. G. Guedes, J. A. Jude, J. Paulin et al., “Airway responsiveness in CD38-deficient mice in allergic airway disease: studies with bone marrow chimeras," American Journal of PhysiologyLung Cellular and Molecular Physiology, vol. 308, no. 5, pp. L485-L493, 2015.

[19] B. Shu, Y. Feng, Y. Gui et al., "Blockade of CD38 diminishes lipopolysaccharide-induced macrophage classical activation and acute kidney injury involving NF- $\kappa \mathrm{B}$ signaling suppression," Cellular Signalling, vol. 42, pp. 249-258, 2018.

[20] Y. M. Wang, Z. Y. Liu, Y. H. Ai, L. N. Zhang, Y. Zou, and Q. Y. Peng, "Blocking the CD38/cADPR pathway plays a doubleedged role in LPS stimulated microglia," Neuroscience, vol. 361, pp. 34-42, 2017.

[21] E. Blacher, T. Dadali, A. Bespalko et al., "Alzheimer's disease pathology is attenuated in a CD38-deficient mouse model," Annals of Neurology, vol. 78, no. 1, pp. 88-103, 2015.

[22] I. Schiavoni, C. Scagnolari, A. L. Horenstein et al., "CD38 modulates respiratory syncytial virus-driven pro-inflammatory processes in human monocyte-derived dendritic cells," Immunology, 2017.
[23] M. A. Berry, B. Hargadon, M. Shelley et al., "Evidence of a role of tumor necrosis factor alpha in refractory asthma," The New England Journal of Medicine, vol. 354, no. 7, pp. 697-708, 2006.

[24] S. C. Erzurum, "Inhibition of tumor necrosis factor alpha for refractory asthma," The New England Journal of Medicine, vol. 354, no. 7, pp. 754-758, 2006.

[25] S. Ying, D. S. Robinson, V. Varney et al., "TNF $\alpha$ mRNA expression in allergic inflammation," Clinical and Experimental Allergy, vol. 21, no. 6, pp. 745-750, 1991.

[26] P. Bradding, J. A. Roberts, K. M. Britten et al., "Interleukin-4, -5 , and -6 and tumor necrosis factor-alpha in normal and asthmatic airways: evidence for the human mast cell as a source of these cytokines," American Journal of Respiratory Cell and Molecular Biology, vol. 10, no. 5, pp. 471-480, 1994.

[27] E. Ferrero, F. Saccucci, and F. Malavasi, "The making of a leukocyte receptor: origin, genes and regulation of human CD38 and related molecules," Chemical Immunology, vol. 75, pp. 1-19, 2000.

[28] K. G. Tirumurugaan, B. N. Kang, R. A. Panettieri, D. N. Foster, T. F. Walseth, and M. S. Kannan, "Regulation of the cd38 promoter in human airway smooth muscle cells by TNF- $\alpha$ and dexamethasone," Respiratory Research, vol. 9, no. 1, p. 26, 2008.

[29] E. Ferrero, F. Saccucci, and F. Malavasi, "The human CD38 gene: polymorphism, CpG island, and linkage to the CD157 (BST-1) gene," Immunogenetics, vol. 49, no. 7-8, pp. 597604, 1999.

[30] E. Ferrero and F. Malavasi, "Human CD38, a leukocyte receptor and ectoenzyme, is a member of a novel eukaryotic gene family of nicotinamide adenine dinucleotide+-converting enzymes: extensive structural homology with the genes for murine bone marrow stromal cell antigen 1 and aplysian ADP-ribosyl cyclase," Journal of Immunology, vol. 159, pp. 3858-3865, 1997.

[31] L. Sun, J. Iqbal, S. Zaidi et al., "Structure and functional regulation of the CD38 promoter," Biochemical and Biophysical Research Communications, vol. 341, no. 3, pp. 804-809, 2006.

[32] K. Mehta, "Retinoid-mediated signaling in CD38 antigen expression," Chemical Immunology, vol. 75, pp. 20-38, 2000.

[33] K. Nata, T. Takamura, T. Karasawa et al., "Human gene encoding CD38 (ADP-ribosyl cyclase/cyclic ADP-ribose hydrolase): organization, nucleotide sequence and alternative splicing," Gene, vol. 186, no. 2, pp. 285-292, 1997.

[34] S. M. Cherepanov, S. Akther, T. Nishimura et al., "Effects of three lipidated oxytocin analogs on behavioral deficits in CD38 knockout mice," Brain Sciences, vol. 7, no. 10, 2017.

[35] D. Hovey, A. Zettergren, L. Jonsson et al., "Associations between oxytocin-related genes and autistic-like traits," Social Neuroscience, vol. 9, no. 4, pp. 378-386, 2014.

[36] F. Ceroni, A. Sagar, N. H. Simpson et al., "A deletion involving CD38 and BST1 results in a fusion transcript in a patient with autism and asthma," Autism Research, vol. 7, no. 2, pp. 254263, 2014.

[37] V. Sathish, M. A. Thompson, S. Sinha, G. C. Sieck, Y. S. Prakash, and C. M. Pabelick, "Inflammation, caveolae and CD38-mediated calcium regulation in human airway smooth muscle," Biochimica et Biophysica Acta, vol. 1843, no. 2, pp. 346-351, 2014.

[38] O. Tliba, G. Damera, A. Banerjee et al., "Cytokines induce an early steroid resistance in airway smooth muscle cells: novel 
role of interferon regulatory factor-1," American Journal of Respiratory Cell and Molecular Biology, vol. 38, no. 4, pp. 463-472, 2008.

[39] D. Jain, S. Keslacy, O. Tliba et al., "Essential role of IFN $\beta$ and $\mathrm{CD} 38$ in TNF $\alpha$-induced airway smooth muscle hyper-responsiveness," Immunobiology, vol. 213, no. 6, pp. 499-509, 2008.

[40] A. J. Abcejo, V. Sathish, D. F. Smelter et al., "Brain-derived neurotrophic factor enhances calcium regulatory mechanisms in human airway smooth muscle," PLoS One, vol. 7, no. 8, article e44343, 2012.

[41] G. C. Sieck, T. A. White, M. A. Thompson, C. M. Pabelick, M. E. Wylam, and Y. S. Prakash, "Regulation of storeoperated $\mathrm{Ca}^{2+}$ entry by $\mathrm{CD} 38$ in human airway smooth muscle," American Journal of Physiology-Lung Cellular and Molecular Physiology, vol. 294, no. 2, pp. L378-L385, 2008.

[42] N. R. Bhakta and P. G. Woodruff, "Human asthma phenotypes: from the clinic, to cytokines, and back again," Immunological Reviews, vol. 242, no. 1, pp. 220-232, 2011.

[43] O. Tliba, D. Deshpande, H. Chen et al., "IL-13 enhances agonist-evoked calcium signals and contractile responses in airway smooth muscle," British Journal of Pharmacology, vol. 140, no. 7, pp. 1159-1162, 2003.

[44] S. Y. Eum, K. Maghni, B. Tolloczko, D. H. Eidelman, and J. G. Martin, "IL-13 may mediate allergen-induced hyperresponsiveness independently of IL-5 or eotaxin by effects on airway smooth muscle," American Journal of Physiology-Lung Cellular and Molecular Physiology, vol. 288, no. 3, pp. L576-L584, 2005.

[45] Y. Amrani, V. Krymskaya, C. Maki, and R. A. Panettieri Jr, "Mechanisms underlying TNF- $\alpha$ effects on agonist-mediated calcium homeostasis in human airway smooth muscle cells," American Journal of Physiology-Lung Cellular and Molecular Physiology, vol. 273, 5, Part 1, pp. L1020-L1028, 1997.

[46] Y. Riffo-Vasquez, S. Pitchford, and D. Spina, "Cytokines in airway inflammation," The International Journal of Biochemistry \& Cell Biology, vol. 32, no. 8, pp. 833-853, 2000.

[47] D. H. Broide, M. Lotz, A. J. Cuomo, D. A. Coburn, E. C. Federman, and S. I. Wasserman, "Cytokines in symptomatic asthma airways," The Journal of Allergy and Clinical Immunology, vol. 89, no. 5, pp. 958-967, 1992.

[48] P. S. Thomas, "Tumour necrosis factor-alpha: the role of this multifunctional cytokine in asthma," Immunology and Cell Biology, vol. 79, no. 2, pp. 132-140, 2001.

[49] P. S. Thomas, D. H. Yates, and P. J. Barnes, “Tumor necrosis factor-alpha increases airway responsiveness and sputum neutrophilia in normal human subjects," American Journal of Respiratory and Critical Care Medicine, vol. 152, no. 1, pp. 76-80, 1995.

[50] P. S. Thomas and G. Heywood, "Effects of inhaled tumour necrosis factor alpha in subjects with mild asthma," Thorax, vol. 57, no. 9, pp. 774-778, 2002.

[51] A. E. John, Y. M. Zhu, C. E. Brightling, L. Pang, and A. J. Knox, "Human airway smooth muscle cells from asthmatic individuals have CXCL8 hypersecretion due to increased NF- $\kappa \mathrm{B}$ $\mathrm{p} 65, \mathrm{C} / \mathrm{EBP} \beta$, and RNA polymerase II binding to the CXCL8 promoter," The Journal of Immunology, vol. 183, no. 7, pp. 4682-4692, 2009.

[52] M. Dileepan, A. E. Sarver, S. P. Rao, R. A. Panettieri Jr, S. Subramanian, and M. S. Kannan, "MicroRNA mediated chemokine responses in human airway smooth muscle cells," PLoS One, vol. 11, no. 3, article e0150842, 2016.
[53] J. Cuenca, C. A. Perez, A. J. Aguirre, I. Schiattino, and J. C. Aguillon, "Genetic polymorphism at position-308 in the promoter region of the tumor necrosis factor (TNF): implications of its allelic distribution on susceptibility or resistance to diseases in the Chilean population," Biological Research, vol. 34, no. 3-4, pp. 237-241, 2001.

[54] B. N. Kang, K. G. Tirumurugaan, D. A. Deshpande et al., "Transcriptional regulation of CD38 expression by tumor necrosis factor- $\alpha$ in human airway smooth muscle cells: role of NF- $\kappa \mathrm{B}$ and sensitivity to glucocorticoids," The FASEB Journal, vol. 20, no. 7, pp. 1000-1002, 2006.

[55] P. J. Barnes, "Drugs for asthma," British Journal of Pharmacology, vol. 147, Supplement 1, pp. S297-S303, 2006.

[56] M. Beato, "Gene regulation by steroid hormones," Cell, vol. 56, no. 3, pp. 335-344, 1989.

[57] I. C. Chikanza, D. Kozaci, and Y. Chernajovsky, "The molecular and cellular basis of corticosteroid resistance," The Journal of Endocrinology, vol. 179, no. 3, pp. 301-310, 2003.

[58] O. Tliba, J. A. Cidlowski, and Y. Amrani, "CD38 expression is insensitive to steroid action in cells treated with tumor necrosis factor- $\alpha$ and interferon- $\gamma$ by a mechanism involving the up-regulation of the glucocorticoid receptor $\beta$ isoform," Molecular Pharmacology, vol. 69, no. 2, pp. 588596, 2006.

[59] W. T. Gerthoffer and C. A. Singer, "MAPK regulation of gene expression in airway smooth muscle," Respiratory Physiology \& Neurobiology, vol. 137, no. 2-3, pp. 237-250, 2003.

[60] R. Issa, S. Xie, N. Khorasani et al., "Corticosteroid inhibition of growth-related oncogene protein-alpha via mitogenactivated kinase phosphatase- 1 in airway smooth muscle cells," The Journal of Immunology, vol. 178, no. 11, pp. 7366-7375, 2007.

[61] R. Issa, S. Xie, K. Y. Lee et al., "GRO- $\alpha$ regulation in airway smooth muscle by IL- $1 \beta$ and TNF- $\alpha$ : role of NF- $\kappa \mathrm{B}$ and MAP kinases," American Journal of Physiology-Lung Cellular and Molecular Physiology, vol. 291, no. 1, pp. L66-L74, 2006.

[62] M. Ramakrishnan, N. L. Musa, J. Li, P. T. Liu, R. G. Pestell, and M. B. Hershenson, "Catalytic activation of extracellular signalregulated kinases induces cyclin D1 expression in primary tracheal myocytes," American Journal of Respiratory Cell and Molecular Biology, vol. 18, no. 6, pp. 736-740, 1998.

[63] O. Tliba, R. A. Panettieri Jr, S. Tliba, T. F. Walseth, and Y. Amrani, "Tumor necrosis factor- $\alpha$ differentially regulates the expression of proinflammatory genes in human airway smooth muscle cells by activation of interferon- $\beta$-dependent CD38 pathway," Molecular Pharmacology, vol. 66, no. 2, pp. 322-329, 2004.

[64] C. C. Wang, W. N. Lin, C. W. Lee et al., "Involvement of p42/ p44 MAPK, p38 MAPK, JNK, and NF- $\kappa$ B in IL- $1 \beta$-induced VCAM-1 expression in human tracheal smooth muscle cells," American Journal of Physiology. Lung Cellular and Molecular Physiology, vol. 288, no. 2, pp. L227-L237, 2005.

[65] L. Zhou, A. Tan, S. Iasvovskaia, J. Li, A. Lin, and M. B. Hershenson, "Ras and mitogen-activated protein kinase kinase kinase-1 coregulate activator protein-1- and nuclear factor- $\kappa \mathrm{B}$-mediated gene expression in airway epithelial cells," American Journal of Respiratory Cell and Molecular Biology, vol. 28, no. 6, pp. 762-769, 2003.

[66] P. J. Barnes, "Corticosteroid effects on cell signalling," The European Respiratory Journal, vol. 27, no. 2, pp. 413-426, 2006. 
[67] P. J. Barnes, "How corticosteroids control inflammation: Quintiles Prize Lecture 2005," British Journal of Pharmacology, vol. 148, no. 3, pp. 245-254, 2006.

[68] C. Jonat, H. J. Rahmsdorf, K. K. Park et al., "Antitumor promotion and antiinflammation: down-modulation of AP-1 (Fos/Jun) activity by glucocorticoid hormone," Cell, vol. 62, no. 6, pp. 1189-1204, 1990.

[69] A. Ray and K. E. Prefontaine, "Physical association and functional antagonism between the p65 subunit of transcription factor NF- $\kappa \mathrm{B}$ and the glucocorticoid receptor," Proceedings of the National Academy of Sciences of the United States of America, vol. 91, no. 2, pp. 752-756, 1994.

[70] R. I. Scheinman, A. Gualberto, C. M. Jewell, J. A. Cidlowski, and A. S. Baldwin Jr, "Characterization of mechanisms involved in transrepression of NF- $\kappa \mathrm{B}$ by activated glucocorticoid receptors," Molecular and Cellular Biology, vol. 15, no. 2, pp. 943-953, 1995.

[71] R. I. Scheinman, P. C. Cogswell, A. K. Lofquist, and A. S. Baldwin Jr, "Role of transcriptional activation of $\mathrm{I} \kappa \mathrm{B} \alpha$ in mediation of immunosuppression by glucocorticoids," Science, vol. 270, no. 5234, pp. 283-286, 1995.

[72] C. C. Franklin and A. S. Kraft, "Conditional expression of the mitogen-activated protein kinase (MAPK) phosphatase MKP1 preferentially inhibits p38 MAPK and stress-activated protein kinase in U937 cells," The Journal of Biological Chemistry, vol. 272, no. 27, pp. 16917-16923, 1997.

[73] R. Furst, T. Schroeder, H. M. Eilken et al., "MAPK phosphatase- 1 represents a novel anti-inflammatory target of glucocorticoids in the human endothelium," The FASEB Journal, vol. 21, no. 1, pp. 74-80, 2007.

[74] O. Kassel, A. Sancono, J. Kratzschmar, B. Kreft, M. Stassen, and A. C. Cato, "Glucocorticoids inhibit MAP kinase via increased expression and decreased degradation of MKP-1," The EMBO Journal, vol. 20, no. 24, pp. 7108-7116, 2001.

[75] J. K. Burgess, J. H. Lee, Q. Ge et al., "Dual ERK and phosphatidylinositol 3-kinase pathways control airway smooth muscle proliferation: differences in asthma," Journal of Cellular Physiology, vol. 216, no. 3, pp. 673-679, 2008.

[76] V. P. Krymskaya, R. B. Penn, M. J. Orsini et al., "Phosphatidylinositol 3-kinase mediates mitogen-induced human airway smooth muscle cell proliferation," American Journal of Physiology-Lung Cellular and Molecular Physiology, vol. 277, no. 1, pp. L65-L78, 1999.

[77] Y. Amrani, A. J. Ammit, and R. A. Panettieri Jr, “Tumor necrosis factor receptor (TNFR) 1, but not TNFR2, mediates tumor necrosis factor- $\alpha$-induced interleukin- 6 and RANTES in human airway smooth muscle cells: role of p38 and p42/44 mitogen-activated protein kinases," Molecular Pharmacology, vol. 60, no. 4, pp. 646-655, 2001.

[78] J. A. Jude, K. G. Tirumurugaan, B. N. Kang, R. A. Panettieri, T. F. Walseth, and M. S. Kannan, "Regulation of CD38 expression in human airway smooth muscle cells: role of class I phosphatidylinositol 3 kinases," American Journal of Respiratory Cell and Molecular Biology, vol. 47, no. 4, pp. 427-435, 2012.

[79] S. Dogan, D. A. Deshpande, T. A. White, T. F. Walseth, and M. S. Kannan, "Regulation of CD 38 expression and function by steroid hormones in myometrium," Molecular and Cellular Endocrinology, vol. 246, no. 1-2, pp. 101-106, 2006.

[80] S. Dogan, D. A. Deshpande, M. S. Kannan, and T. F. Walseth, "Changes in CD38 expression and ADP-ribosyl cyclase activity in rat myometrium during pregnancy: influence of sex steroid hormones," Biology of Reproduction, vol. 71, no. 1, pp. 97-103, 2004.

[81] S. Dogan, T. A. White, D. A. Deshpande, M. P. Murtaugh, T. F. Walseth, and M. S. Kannan, "Estrogen increases CD38 gene expression and leads to differential regulation of adenosine diphosphate (ADP)-ribosyl cyclase and cyclic ADPribose hydrolase activities in rat myometrium," Biology of Reproduction, vol. 66, no. 3, pp. 596-602, 2002.

[82] T. El-Hamoly, D. M. El-Sharawy, M. S. El Refaye, and S. S. Abd El-Rahman, "L-thyroxine modifies nephrotoxicity by regulating the apoptotic pathway: the possible role of CD38/ADPribosyl cyclase-mediated calcium mobilization," PLoS One, vol. 12, no. 9, article e0184157, 2017.

[83] R. J. MacDonald, J. H. Shrimp, H. Jiang, L. Zhang, H. Lin, and A. Yen, "Probing the requirement for CD38 in retinoic acidinduced HL-60 cell differentiation with a small molecule dimerizer and genetic knockout," Scientific Reports, vol. 7, no. 1, article 17406, 2017.

[84] J. H. Lee, J. Zhang, G. A. Massmann, and J. P. Figueroa, "Antenatal betamethasone increases vascular reactivity to endothelin-1 by upregulation of CD38/cADPR signaling," Journal of Developmental Origins of Health and Disease, vol. 5, no. 01, pp. 56-62, 2014.

[85] Y. Chiba, M. Tanabe, K. Goto, H. Sakai, and M. Misawa, "Down-regulation of miR-133a contributes to up-regulation of Rhoa in bronchial smooth muscle cells," American Journal of Respiratory and Critical Care Medicine, vol. 180, no. 8, pp. 713-719, 2009.

[86] T. X. Lu, J. Hartner, E. J. Lim et al., "MicroRNA-21 limits in vivo immune response-mediated activation of the IL-12/ IFN- $\gamma$ pathway, Th1 polarization, and the severity of delayed-type hypersensitivity," The Journal of Immunology, vol. 187, no. 6, pp. 3362-3373, 2011.

[87] T. X. Lu, A. Munitz, and M. E. Rothenberg, "MicroRNA-21 is up-regulated in allergic airway inflammation and regulates IL12p35 expression," The Journal of Immunology, vol. 182, no. 8, pp. 4994-5002, 2009.

[88] R. T. Martinez-Nunez, F. Louafi, and T. Sanchez-Elsner, "The interleukin 13 (IL-13) pathway in human macrophages is modulated by microRNA-155 via direct targeting of interleukin 13 receptor $\alpha 1$ (IL13R $\alpha 1)$," The Journal of Biological Chemistry, vol. 286, no. 3, pp. 1786-1794, 2011.

[89] T. Pagdin and P. Lavender, "MicroRNAs in lung diseases," Thorax, vol. 67, no. 2, pp. 183-184, 2012.

[90] D. P. Bartel, "MicroRNAs: genomics, biogenesis, mechanism, and function," Cell, vol. 116, no. 2, pp. 281-297, 2004.

[91] S. Maltby, M. Plank, H. L. Tay, A. Collison, and P. S. Foster, "Targeting microRNA function in respiratory diseases: minireview," Frontiers in Physiology, vol. 7, p. 21, 2016.

[92] A. Ebrahimi and E. Sadroddiny, "MicroRNAs in lung diseases: recent findings and their pathophysiological implications," Pulmonary Pharmacology \& Therapeutics, vol. 34, pp. 55-63, 2015.

[93] J. A. Jude, M. Dileepan, S. Subramanian et al., "miR-140-3p regulation of TNF- $\alpha$-induced CD38 expression in human airway smooth muscle cells," American Journal of PhysiologyLung Cellular and Molecular Physiology, vol. 303, no. 5, pp. L460-L468, 2012.

[94] M. Dileepan, J. A. Jude, S. P. Rao et al., "MicroRNA-708 regulates CD38 expression through signaling pathways JNK MAP kinase and PTEN/AKT in human airway smooth muscle cells," Respiratory Research, vol. 15, no. 1, p. 107, 2014. 
[95] Z. Chun-Zhi, H. Lei, Z. An-Ling et al., "MicroRNA-221 and microRNA-222 regulate gastric carcinoma cell proliferation and radioresistance by targeting PTEN," BMC Cancer, vol. 10, no. 1, p. 367, 2010.

[96] P. Damania, B. Sen, S. B. Dar et al., "Hepatitis B virus induces cell proliferation via HBx-induced microRNA-21 in hepatocellular carcinoma by targeting programmed cell death protein4 (PDCD4) and phosphatase and tensin homologue (PTEN)," PLoS One, vol. 9, no. 3, article e91745, 2014. 


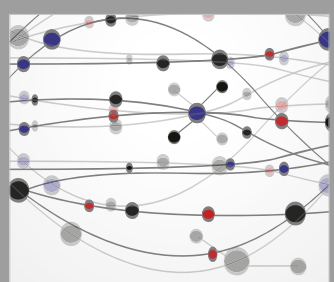

The Scientific World Journal
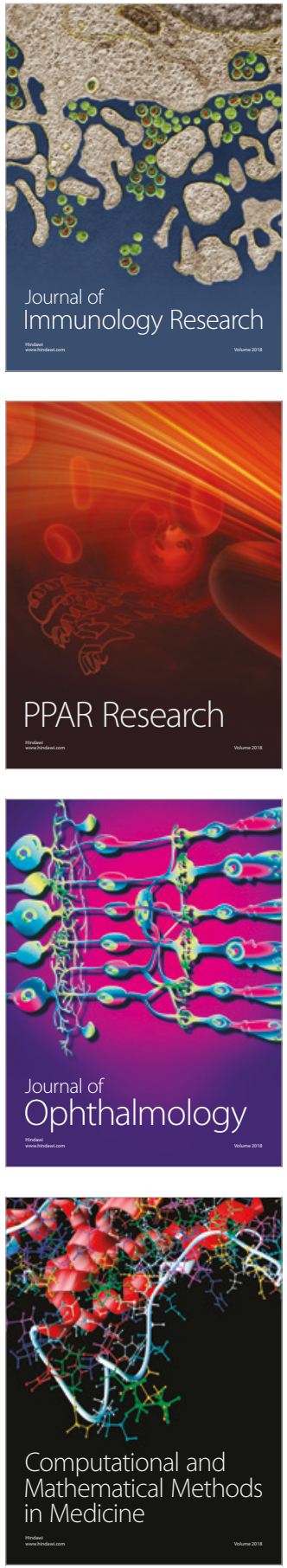

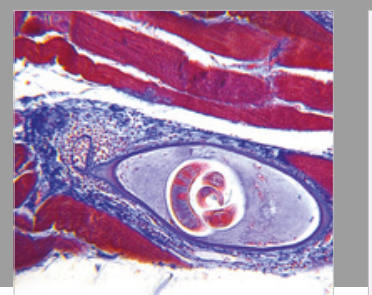

Gastroenterology Research and Practice

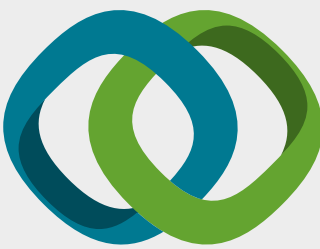

\section{Hindawi}

Submit your manuscripts at

www.hindawi.com
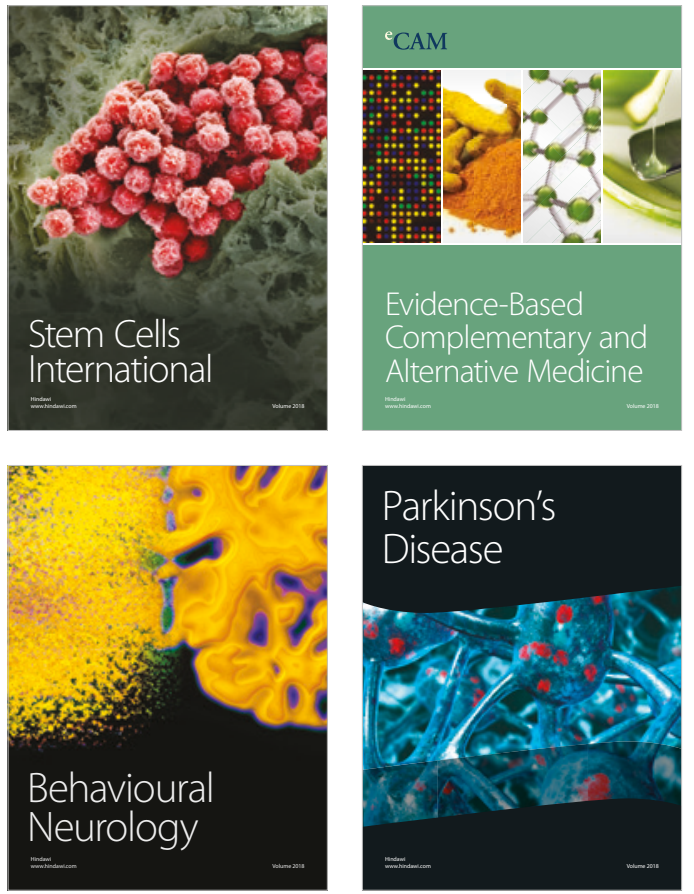

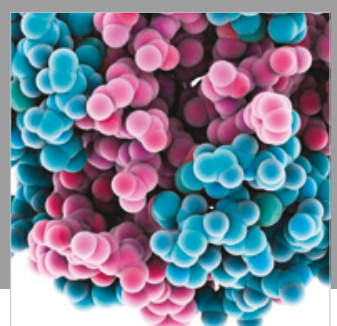

ournal of

Diabetes Research

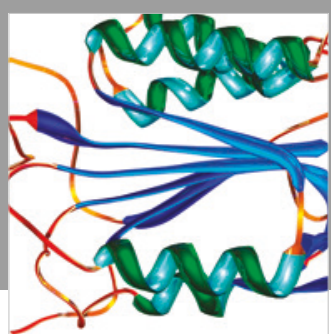

Disease Markers
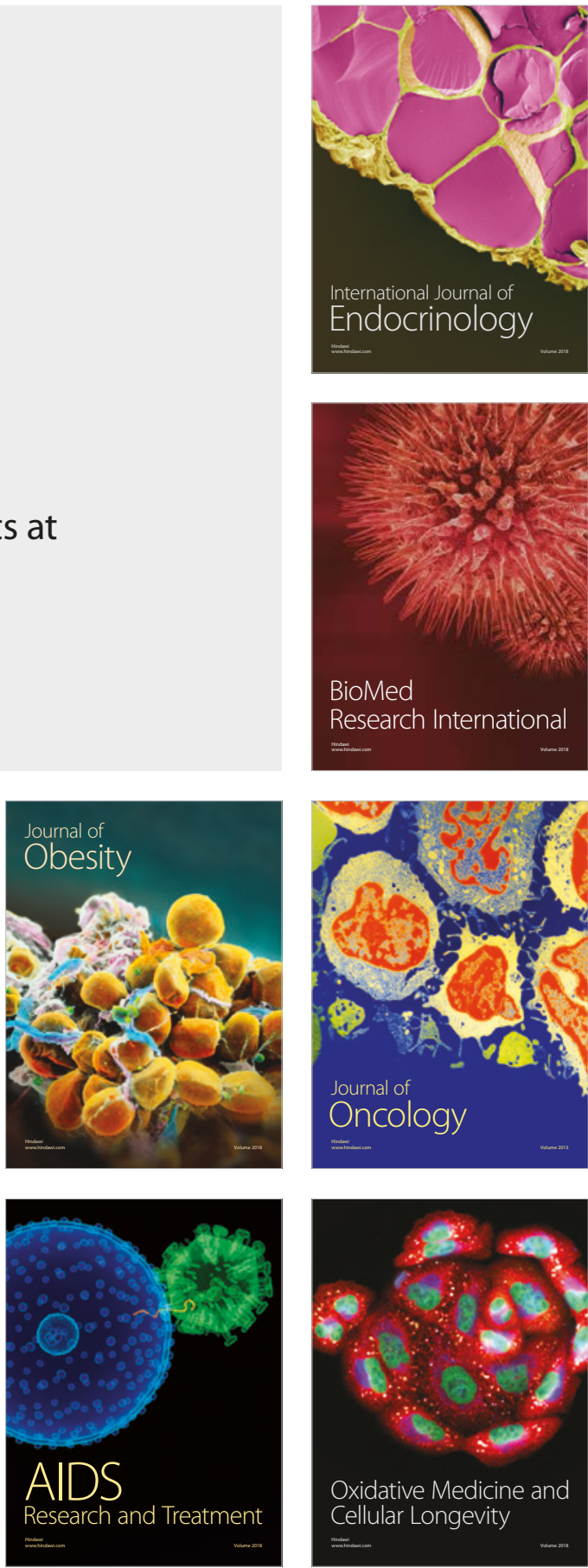